\title{
A randomized trial of yoga for adolescents with irritable bowel syndrome
}

\author{
Leora Kuttner $\mathrm{PhD}^{1}$, Christine T Chambers $\mathrm{PhD}^{1,2}$, Janine Hardial $\mathrm{BSc}^{2}$, David M Israel MD ${ }^{1,3}$, \\ Kevan Jacobson $\mathrm{MBBCh}^{1,3}$, Kathy Evans $\mathrm{BSN}^{3}$
}

L Kuttner, CT Chambers, J Hardial, DM Israel, K Jacobson, K Evans. A randomized trial of yoga for adolescents with irritable bowel syndrome. Pain Res Manage 2006;11(4):217-223.

BACKGROUND: Adolescents with irritable bowel syndrome (IBS) frequently experience interference with everyday activities. Mindbody approaches such as yoga have been recommended as interventions for patients with IBS. Despite promising results among adult samples, there have been limited studies exploring the efficacy of yoga with pediatric patients.

OBJECTIVE: To conduct a preliminary randomized study of yoga as treatment for adolescents with IBS.

METHODS: Twenty-five adolescents aged 11 to 18 years with IBS were randomly assigned to either a yoga or wait list control group. Before the intervention, both groups completed questionnaires assessing gastrointestinal symptoms, pain, functional disability, coping, anxiety and depression. The yoga intervention consisted of a $1 \mathrm{~h}$ instructional session, demonstration and practice, followed by four weeks of daily home practice guided by a video. After four weeks, adolescents repeated the baseline questionnaires. The wait list control group then received the yoga intervention and four weeks later completed an additional set of questionnaires.

RESULTS: Adolescents in the yoga group reported lower levels of functional disability, less use of emotion-focused avoidance and lower anxiety following the intervention than adolescents in the control group. When the pre- and postintervention data for the two groups were combined, adolescents had significantly lower scores for gastrointestinal symptoms and emotion-focused avoidance following the yoga intervention. Adolescents found the yoga to be helpful and indicated they would continue to use it to manage their IBS.

CONCLUSIONS: Yoga holds promise as an intervention for adolescents with IBS.

Keywords: Adolescents; Irritable bowel syndrome (IBS); Mindbody; Recurrent abdominal pain; Yoga

Tritable bowel syndrome (IBS) is a recurrent condition characterized by abdominal pain accompanied by diarrhea, gas and bloating. It is estimated that IBS affects $8 \%$ to $14 \%$ of the population and is the most common of all gastrointestinal ailments (1). Among pediatric samples, data indicate that IBS is experienced by approximately 17\% of high school children and $8 \%$ of middle school children (2). Children with this recurring syndrome frequently experience interference with day-to-day activities, such as missed school, withdrawal from physical activities, mood disturbances (eg, anxiety and depression) and disruptions in peer relationships (2-4).

\section{Un essai aléatoire du yoga pour des adoles- cents atteints du syndrome du côlon irritable}

HISTORIQUE : Les adolescents atteints du syndrome du côlon irritable (SCI) sont souvent perturbés dans leurs activités quotidiennes. Des démarches de l'esprit et du corps comme le yoga sont des interventions recommandées chez les patients atteints du SCI. Malgré des résultats prometteurs chez les adultes, les études explorant l'efficacité du yoga auprès des patients pédiatriques sont limitées.

OBJECTIF : Mener une étude aléatoire préliminaire du yoga comme traitement des adolescents atteints du SCI.

MÉTHODOLOGIE : Vingt-cinq adolescents de 11 à 18 ans atteints du SCI ont été divisés de manière aléatoire entre le yoga et un groupe témoin sur la liste d'attente. Avant l'intervention, les deux groupes ont rempli des questionnaires visant à évaluer leurs symptômes gastro-intestinaux, leur douleur, leur invalidité fonctionnelle, leur mécanisme d'adaptation, leur anxiété et leur dépression. L'intervention de yoga était constituée d'une séance d'enseignement, de démonstration et de pratique du yoga d'une heure, suivie de quatre semaines d'exercice quotidien orienté par vidéo à la maison. Au bout de quatre semaines, les adolescents répondaient de nouveau au questionnaire de départ. Les patients sur la liste d'attente ont alors reçu l'intervention de yoga pendant quatre semaines, et quatre semaines plus tard, ils ont rempli un nouveau questionnaire.

RÉSULTATS : Les adolescents faisant partie du groupe de yoga avaient tendance à déclarer un niveau d'incapacité fonctionnelle moins élevé, un moins grand usage de l'évitement axé sur l'émotion et moins d'anxiété après l'intervention que les adolescents du groupe témoin. Lorsqu'on combinait les données avant et après l'intervention des deux groupes, les adolescents obtenaient des niveaux significativement plus faibles de symptômes gastro-intestinaux et d'évitement axé sur l'émotion après l'intervention de yoga. Les adolescents trouvaient le yoga utile et ont affirmé qu'ils continueraient de le pratiquer pour prendre en charge leur SCI. CONCLUSIONS : Le yoga est prometteur comme intervention pour les adolescents atteints du SCI.

${ }^{1}$ University of British Columbia; ${ }^{2}$ British Columbia Research Institute for Children's and Women's Health; ${ }^{3}$ Division of Gastroenterology, British Columbia Children's Hospital, Vancouver, British Columbia

Correspondence: Dr Leora Kuttner, \#204-1089 West Broadway, Vancouver, British Columbia V6H 1E5. Telephone 604-736-8801,

fax604-734-4660, e-mail kuttner@sfu.ca 
imaging studies (9) suggest that IBS patients differ from healthy controls in that those with IBS show an activation of pain amplification regions with no activation of inhibitory pain areas, leading to visceral hypersensitivity. Mayer (9) suggests a disruption model for intervention with this brain-gut axis in which pain persistence is disrupted by either pharmacology or mind-body therapies, such as hypnosis. While the exact mechanism leading to the clinical entity of IBS is not fully known, it is clear that both physiological and emotional factors are integrated in a complex way to modulate the symptoms in any given individual.

Many different interventions have been recommended to manage IBS, including nutrition, exercise, medication, behaviour modification and emotional support (1). Little research, however, has systematically examined these interventions among pediatric patients. As a result, no reliable evidencebased treatment intervention exists to help children and adolescents with IBS alter their maladaptive patterns, reduce pain and distress, and increase participation in daily living activities.

Recently, mind-body approaches such as hypnosis have been recommended as holding considerable promise as meaningful and cost-effective interventions for adult patients with IBS (10). Mind-body approaches also include tai-chi, meditation and yoga, among others. Yoga is one of the most commonly practiced mind-body practices, with an estimated 15 million American adults having used yoga in the past year (11). Nearly $50 \%$ of adults who have used yoga report that they have used it to manage a health condition (11). Of the various forms or systems of yoga that have evolved over the centuries, the more active form of yoga, Hatha yoga, involves physical poses and controlled breathing. One of the most common forms of Hatha yoga practiced in North America is Iyengar. The main component of the practice of Iyengar is the poses, or, in Sanskrit, 'asanas'. In essence, a person will assume a number of stationary poses that use contraction and relaxation of different muscles to create specific body alignments (12). The physical postures with breathing and meditative techniques involved in yoga are intended to reduce anxiety, improve body tone and increase feelings of well-being (13).

An increasing number of studies have examined the effectiveness of yoga among adults for managing painful conditions such as migraine $(14,15)$, carpal tunnel syndrome (16), osteoarthritis (17) and multiple sclerosis (12), as well as other health conditions, such as asthma (18), hypertension (19) and chronic low back pain (20). After 16 weeks of Iyengar yoga, Williams et al (20) found a significant decrease in pain and functional disability associated with chronic back pain. Among adult patients with IBS, yoga was recently found to decrease bowel symptoms and anxiety, and enhance parasympathetic reactivity (21).

Of the limited research involving pediatric samples, yoga has been used to improve posture among children with physical malformations (22) and to treat anxiety in child and adolescent psychiatric patients (23). Yoga has been found to improve children's hyperactive and inattentive behaviour, selfesteem and relationship quality with parents (24). Additionally, Telles and Srinivas (25) found yoga to decrease physiological anxiety among children with vision impairments. Similarly, Jain et al (26) found that yoga exercises in adolescents who had childhood asthma resulted in an increase in pulmonary function and exercise capacity. A published abstract by Raghavan et al (27) reported the results of a four-month yoga protocol among a small group of young adults (aged 15 to 22 years) with IBS. They found decreased illness perception and increased general well-being, but no direct improvements in IBS symptoms. However, the results of this preliminary study were based on the randomization of a total of only seven IBS patients to either a yoga intervention or wait list control group, and no statistical analyses were reported. Anecdotal reports of the use of yoga with children with IBS in our clinical practice suggest the potential for efficacious outcomes; however, controlled research is needed to systematically examine yoga as a potential treatment for IBS.

The purpose of the present study was to determine whether an instructional session in yoga followed by four weeks of daily yoga practice using a video of selected yoga poses (asanas) for abdominal comfort would result in a reduction in pain, gastrointestinal symptoms and functional disability (primary outcomes) among adolescents with IBS when compared with a wait list control group. In addition, the effects of yoga on pain coping, anxiety and depression were also explored (secondary outcomes). It was expected that adolescents who received the yoga treatment would report lower scores in each of these domains following the yoga interventions when compared with those in the control group.

\section{Participants}

\section{METHODS}

Adolescents were recruited from either the gastroenterology clinic at the local children's hospital $(n=9)$ or through the community via posters $(n=19)$. Participants had to self-identify as having abdominal pain and meet criteria for IBS via telephone screening to be eligible to participate in the study. The university and hospital ethical review committees approved the study.

Twenty-eight adolescents (eight boys and 20 girls) between the ages of 11 and 18 years (mean age $14.15 \pm 1.95$ years) who met the Rome I criteria for IBS (28) were enrolled in the study and were randomly assigned to either the yoga intervention group $(n=14$; 12 girls and two boys) or the wait list control group ( $n=14$; eight girls and six boys). The Rome I criteria for IBS were applied given concerns that the Rome II criteria are unnecessarily restrictive for research and practice (29). The average age of those in the yoga group and control group was $14.36 \pm 2.10$ and $13.83 \pm 1.89$ years, respectively. Of those in the yoga group, 13 self-identified as Caucasian and one as First Nations. Three boys dropped out of the control group and were excluded from analyses, resulting in a final sample size of $n=11$ for the control group, which included nine Caucasians, one Asian and one Indo-Canadian. This sample size was calculated to be sufficient to detect large effects sizes for between-groups analyses and moderate-to-small effects sizes for the within-subjects analyses (30).

\section{Measures}

Pain intensity: Adolescents provided a rating of their general level of pain intensity over the past month using a 0 to 10 numeric rating scale.

Gastrointestinal symptoms: Adolescents rated their level of IBS symptoms (eg, diarrhea and bloating) over the last month using a checklist developed by Blanchard and Scharff (31). Total symptom scores ranged from 0 to 3 .

Functional Disability Inventory (32): The Functional Disability Inventory is a 15-item questionnaire for school-age children and adolescents that assesses levels of pain- and illness-related 
interference with activities of daily living. Items are rated on a five-point scale $(0=$ 'none' and $4=$ 'impossible'). A total score (ranging from 0 to 60 ) is obtained by summing item responses.

Pain Coping Questionnaire (33): The Pain Coping Questionnaire is a 39-item questionnaire validated for use with children and adolescents in assessing pain coping strategies. Items are rated on a five-point scale ( $0=$ 'never' to 4 = 'very often'). Factor analyses support an underlying structure of three scales: Approach Coping (eg, information seeking and problem-solving), Distraction (eg, behavioural distraction and cognitive distraction) and Emotion-Focused Avoidance (eg, externalizing, internalizing). Scores for each of the three scales (ranging from 0 to 4 ) were obtained by averaging responses to appropriate items.

Revised Child Manifest Anxiety Scale (34): The Revised Child Manifest Anxiety Scale is a 37-item measure of anxiety symptoms in children and adolescents. Items are rated as present or absent. A total anxiety score (ranging from 0 to 31 ) is calculated by summing the number of anxiety items endorsed as present (items from an additional six items assessing response style are not included in the total anxiety score).

Children's Depression Inventory - Short Form (35): The Children's Depression Inventory - Short Form is a 10-item questionnaire. For each item, children select from among three statements the one that best describes how they have been feeling in the last two weeks. Scores are assigned from 0 to 2. A total score (ranging from 0 to 20 ) is obtained by summing item responses.

\section{Procedure}

A structured telephone screening by a trained research assistant was conducted with each adolescent and one of their parents to confirm eligibility for the study (ie, age 11 to 18 years, meeting diagnostic criteria for IBS, English-speaking, with a television and video cassette player at home). Subsequently, adolescents were randomly assigned to either the yoga intervention or wait list control group using a sequence of randomly determined numbers. On the day of the intervention, informed written consent was obtained from parents and written and verbal assent was obtained from adolescents. Adolescents in both groups provided basic demographic information (ie, age, sex and ethnicity) and completed a series of questionnaires consisting of the measures described above.

After completing the questionnaires, the yoga group participated in a $1 \mathrm{~h}$ instructional session that included verbal instruction, videotaped and live demonstration, and assisted practice with a yoga teacher (certified in Hatha and Iyengar). The yoga intervention consisted of a brief introduction to yoga as well as watching and participating in the yoga video program. In the video, a yoga teacher and two adolescents demonstrated a series of poses that required a total of $10 \mathrm{~min}$ to complete. All participants were given the same poses and breathing instructions (Table 1), selected for the purported easing and self regulation on the abdomen and bowel. The series began with lying prone using focused abdominal breathing, and proceeded through a series that included poses known as the cat, the child, the bridge, sitting twists and standing forward bend, all accompanied by regulated deep relaxed breathing, while attuning to abdominal sensory changes and releasing tension. If pain was experienced the participants were instructed "to notice how your belly feels during the pose". The instructor often gave the adolescents cues to focus on where they currently felt or tended to feel pain. Examples included: "Take a deep breath in and as you exhale, begin to let the pain out" and "rub your hands together making them warm and put them on your body where you feel pain or tightness." (Copies of the yoga video are available to patients and professionals from the first author at a cost of $\$ 25$ per video to cover dubbing and postal charges.) This yoga video, designed by the authors for adolescents with IBS, was provided to each adolescent to take home for daily practice over four weeks. Adolescents in the wait list group were asked to manage their IBS as they typically would during this fourweek period. Adolescents in both groups completed the same questionnaires at baseline at the end of the four-week period. The wait list group subsequently received the yoga intervention and completed a final set of questionnaires following their four weeks of home practice.

Adolescents were asked to rate, using a series of 0 to 10 scales, how frequently they practiced the yoga $(0=$ 'never' to $10=$ 'every day'), how helpful they found the yoga $(0=$ 'not at all' to $10=$ 'extremely'), how enjoyable they found the yoga $(0$ = 'really didn't like it' to $10=$ 'really liked it'), and how easy the yoga was to do $(0=$ 'very hard' to $10=$ 'very easy'). Adolescents were asked to indicate (by answering 'yes' or 'no') whether they planned to continue using yoga to manage their IBS. Adolescents were also asked open-ended questions regarding perceived areas of improvement and barriers to regular yoga practice.

It is noted that, due to the small sample size and to maximize data, missing values were replaced with mean values (36) for the group, if the participant was missing item responses that precluded calculation of questionnaire scores. A total number of 21 missing data points across participants were substituted. Data were excluded when the number of missing items on a questionnaire exceeded $20 \%$. As a result, data were not available for two participants for depression and one participant for anxiety at baseline, and one participant in the wait list group for depression at the second follow-up (postintervention).

\section{RESULTS}

A series of independent sample $t$ tests for the continuous measures (eg, child's age) and a series of $\chi^{2}$ analyses for the categorical measures (eg, child's ethnicity) were conducted to examine group differences in demographic characteristics of the two groups. There were no significant group differences $(P>0.10)$ for any of the variables, indicating that the random assignment was successful in ensuring equivalency in the demographic characteristics of the two groups. However, when $t$ tests were conducted to examine equivalency in the responses to the various baseline questionnaires, a significant difference in pain intensity between the two groups was found (Table 2), with the wait list group reporting on average higher levels of pain intensity in the preceding month than the yoga group. There were no other significant group differences in the baseline measures. As a result of the significant difference in pain intensity at baseline, the possibility of including pain intensity as a covariate in subsequent analyses was explored. Because no differences in the outcome of the analysis emerged, whether pain intensity was used as a covariate or not, the results of the analysis without the covariate are presented below, for simplicity. However, given the difference at baseline, pain intensity was omitted as an outcome variable in the comparison of the two groups following the intervention.

The means and standard deviations for the adolescents' scores on the various follow-up questionnaires after the yoga group had received the intervention also appear in Table 2. A multivariate ANOVA was used to examine group differences 
TABLE 1

Summary of yoga poses and breathing instructions

\begin{tabular}{|c|c|c|c|}
\hline Sanskrit/English Name & Position description & Breathing instructions & Duration \\
\hline Savasana/Corpse pose & Lying on back with knees bent & $\begin{array}{l}\text { Deep breath in, filling your body with } \\
\text { breath, exhale to help the pain move out }\end{array}$ & 7 breaths \\
\hline $\begin{array}{l}\text { Jathara Parivart-anasana/ } \\
\text { Intense abdominal twist }\end{array}$ & $\begin{array}{l}\text { Lying on back, knees to chest } \\
\text { and rock from side to side }\end{array}$ & None specifically & Unspecified \\
\hline Paranamuktasana/Knees to chest & $\begin{array}{l}\text { Lying on back, hug bent legs, bring } \\
\text { forehead and knees towards each other }\end{array}$ & $\begin{array}{l}\text { Hug legs, take a deep inhalation, } \\
\text { exhale bringing knees and forehead together }\end{array}$ & Unspecified \\
\hline Savasana variation/Corpse pose & $\begin{array}{l}\text { Lying on back with knees bent, } \\
\text { arms clasped behind head. Lift head }\end{array}$ & $\begin{array}{l}\text { Deep inhalation, exhale, lift head up for two } \\
\text { breaths, put head down on last exhalation }\end{array}$ & 3 breaths \\
\hline $\begin{array}{l}\text { Jathara Parivart-anasana/ } \\
\text { Intense abdominal twist with arms }\end{array}$ & $\begin{array}{l}\text { Lying on back, arms spread like } \\
\text { airplane wings, knees roll to right and left }\end{array}$ & $\begin{array}{l}\text { Breathe in and let both knees roll gently } \\
\text { to the right (and left) }\end{array}$ & 2 breaths each side \\
\hline Bidalsana/Cat posture & $\begin{array}{l}\text { On all fours, round back, raise belly, } \\
\text { release, arch back, look upwards, curl } \\
\text { back again like a cat }\end{array}$ & $\begin{array}{l}\text { Breathe out. If it feels good, } \\
\text { raise your belly up and when you release } \\
\text { your lungs fill automatically, breathe out. } \\
\text { As you arch your back, breathe in }\end{array}$ & 6 times \\
\hline Balasana/Pose of the child & $\begin{array}{l}\text { On all fours bring bottom to heels, head } \\
\text { on the floor }\end{array}$ & $\begin{array}{l}\text { Breathe easily and fully as your body } \\
\text { rebalances }\end{array}$ & Unspecified \\
\hline $\begin{array}{l}\text { Baddha Konasana (with rocking)/ } \\
\text { Bound ankle pose }\end{array}$ & $\begin{array}{l}\text { Sitting, soles of feet together, grab } \\
\text { ankles/shins and rock from side to side }\end{array}$ & Keep your breath full and easy & Unspecified \\
\hline $\begin{array}{l}\text { Parivritta Sukhasana/Comfortable } \\
\text { simple crossed legs with a twist }\end{array}$ & $\begin{array}{l}\text { Sitting tall, make spine long, place } \\
\text { right hand on floor behind, turn to the } \\
\text { right and place left hand on right leg }\end{array}$ & $\begin{array}{l}\text { Inhale deeply when placing hand } \\
\text { behind and exhale when turning and } \\
\text { and putting hand on other leg }\end{array}$ & $\begin{array}{l}\text { Hold for } 3 \text { breaths } \\
\text { each side }\end{array}$ \\
\hline $\begin{array}{l}\text { Adhomukha Baddhakanasana/ } \\
\text { Seated bound ankle pose }\end{array}$ & $\begin{array}{l}\text { Sitting, hold onto feet, lengthen } \\
\text { through spine, exhale and roll forward; } \\
\text { let head hang down }\end{array}$ & Inhale to lengthen your spine & $\begin{array}{l}3 \text { to } 4 \text { breaths when } \\
\text { head is down }\end{array}$ \\
\hline $\begin{array}{l}\text { Tadasana (with arms swinging)/ } \\
\text { Mountain pose }\end{array}$ & $\begin{array}{l}\text { Standing firmly grounded, feet wider } \\
\text { than hips, swing hands around body }\end{array}$ & No specific instruction given & Unspecified \\
\hline $\begin{array}{l}\text { Parsvaparvatasana in Tadasana/ } \\
\text { Mountain pose with stretched } \\
\text { arms and side bend }\end{array}$ & $\begin{array}{l}\text { Standing, lift arms over head, } \\
\text { clasp fingers and stretch tall. } \\
\text { Fold over to one side, return to centre } \\
\text { and fold to other side }\end{array}$ & $\begin{array}{l}\text { Breathe in as you clasp fingers, } \\
\text { exhale, breathe in when at centre and } \\
\text { exhale from side to side }\end{array}$ & 4 each side \\
\hline Tension release & $\begin{array}{l}\text { Hands at side, shaking to let any } \\
\text { tension go }\end{array}$ & No specific instruction given & Unspecified \\
\hline $\begin{array}{l}\text { Uttanasana/Standing } \\
\text { forward bend }\end{array}$ & $\begin{array}{l}\text { On softly bent knees, drop chin } \\
\text { to chest fold down forward. } \\
\text { Move head from side to side }\end{array}$ & Take 3 full breaths (in forward bend) & $\begin{array}{l}\text { Stay in forward bend } \\
\text { for } 3 \text { breaths }\end{array}$ \\
\hline Badasana/Bridge pose & $\begin{array}{l}\text { Lying on back with knees bent, } \\
\text { place arms at side, raise hips to } \\
\text { make an inclined bridge }\end{array}$ & $\begin{array}{l}\text { Inhale deeply when arms placing arms } \\
\text { at sides and exhale as you raise your hips }\end{array}$ & $\begin{array}{l}\text { Hold inclined bridge } \\
\text { for } 2 \text { to } 3 \text { breaths }\end{array}$ \\
\hline $\begin{array}{l}\text { Pavanamuktasana/ } \\
\text { Holding knee to chest }\end{array}$ & $\begin{array}{l}\text { Embrace legs and curl one at a time } \\
\text { and bring head and knees together }\end{array}$ & No specific instruction given & Unspecified \\
\hline $\begin{array}{l}\text { Savasana (modified with knees } \\
\text { bent to enhance comfort/ } \\
\text { Corpse pose }\end{array}$ & $\begin{array}{l}\text { Lying on your back let bent knees } \\
\text { rest against each other, hands where } \\
\text { they feel comfortable and make } \\
\text { sounds "ah", "oo", with eyes closed }\end{array}$ & $\begin{array}{l}\text { Make sounds with out-breath } \\
\text { creating good energy }\end{array}$ & 10 breaths \\
\hline
\end{tabular}

on these measures. Although the convention for statistical significance is a cut-off of $\mathrm{P}<0.05$, given the exploratory and preliminary nature of the present study, differences significant at $\mathrm{P}<0.10$ or less were considered to be reflective of statistical trends worthy of interpretation as is commonplace for preliminary or pilot studies. For example, Garfinkel at al (16) conducted a pilot study examining the efficacy of yoga as a treatment for carpal tunnel syndrome; they set the significance level at $\mathrm{P}<0.10$ and interpreted their results as meaningful statistical trends worthy of further study.
As shown in Table 2, adolescents who received the yoga intervention tended to report lower levels of functional disability $(\mathrm{F}[1,23]=3.52, \mathrm{P}=0.073)$, lower levels of emotionfocused avoidance $(F[1,23]=3.13, \mathrm{P}=0.09)$ and lower levels of anxiety $(\mathrm{F}[1,23]=3.134, \mathrm{P}=0.09)$ than adolescents in the control group. There were no group differences in adolescents' use of approach coping $(\mathrm{F}[1,23]=0.026, \mathrm{P}=0.87)$, distraction strategies $(\mathrm{F}[1,23]=1.58, \mathrm{P}=0.22)$, depression $(\mathrm{F}[1,23]=1.26$, $\mathrm{P}=0.27$ ) or overall gastrointestinal symptoms over the fourweek period $(\mathrm{F}[1,23]=1.90, \mathrm{P}=0.18)$. 
TABLE 2

Outcome measures for yoga and wait list control groups at baseline and four-week follow-up

\begin{tabular}{|c|c|c|c|c|}
\hline & \multicolumn{2}{|c|}{ Yoga group $(n=14)$} & \multicolumn{2}{|c|}{$\begin{array}{l}\text { Wait list control } \\
\text { group }(n=11)\end{array}$} \\
\hline & Baseline & Follow-up & Baseline & Follow-up \\
\hline \multicolumn{5}{|c|}{ Primary outcomes } \\
\hline GI symptoms & $1.34 \pm 0.41$ & $1.11 \pm 0.73$ & $1.64 \pm 0.77$ & $1.52 \pm 0.74$ \\
\hline Pain intensity & $4.93 \pm 1.74^{*}$ & - & $6.82 \pm 2.40^{*}$ & - \\
\hline FDI & $24.87 \pm 12.85$ & $24.36 \pm 12.90^{\dagger}$ & $31.55 \pm 11.60$ & $34.00 \pm 12.55^{\dagger}$ \\
\hline \multicolumn{5}{|c|}{ Secondary outcomes } \\
\hline CDI & $3.25 \pm 2.18$ & $2.64 \pm 1.95$ & $4.36 \pm 4.15$ & $4.27 \pm 5.00$ \\
\hline RCMAS & $10.90 \pm 5.32$ & $10.64 \pm 5.20^{\dagger}$ & $14.62 \pm 7.19$ & $14.75 \pm 6.42^{\dagger}$ \\
\hline \multicolumn{5}{|l|}{$P C Q$} \\
\hline $\begin{array}{l}\text { Emotion- } \\
\text { focused } \\
\text { avoidance }\end{array}$ & $1.29 \pm 0.58$ & $1.07 \pm 0.54^{\dagger}$ & $1.64 \pm 0.87$ & $1.66 \pm 1.10^{\dagger}$ \\
\hline Distraction & $2.14 \pm 1.66$ & $2.18 \pm 0.94$ & $1.66 \pm 0.98$ & $1.69 \pm 0.98$ \\
\hline Approach & $1.87 \pm 0.58$ & $1.92 \pm 0.73$ & $1.83 \pm 0.70$ & $1.87 \pm 0.80$ \\
\hline \multicolumn{5}{|c|}{$\begin{array}{l}\text { Results are presented as mean } \pm S D \text {. *Significant mean difference between } \\
\text { groups at baseline, } P<0.10 \text {; + Significant mean difference between the yoga } \\
\text { and wait list control groups at follow-up, } P<0.10 \text {. Note: Data for pain intensity } \\
\text { at follow-up are not presented or analyzed because there was a significant } \\
\text { difference between these groups at baseline. Children's Depression } \\
\text { Inventory (CDI) data were missing for two participants in the yoga condition at } \\
\text { baseline. Revised Child Manifest Anxiety Scale (RCMAS) data were missing } \\
\text { for one participant in the wait list condition at baseline. FDI Functional } \\
\text { Disability Inventory; GI Gastrointestinal; PCQ Pain Coping Questionnaire }\end{array}$} \\
\hline
\end{tabular}

After the wait list control group participated in the yoga intervention, their data were merged with that of the yoga group to allow for a global examination of pre- and postintervention effects using a series of paired samples $t$ tests for the entire sample. Table 3 provides a summary of the means, standard deviations and results of the $t$ tests. As the table illustrates, there was a significant reduction in reports of gastrointestinal symptoms $(t[1,24]=3.15, \mathrm{P}<0.01)$ and a trend for lower levels of emotion-focused avoidance $(t[1,24]=2.82, \mathrm{P}=0.10)$ following participation in the yoga intervention.

Following completion of the yoga intervention, adolescents indicated that they had practiced the yoga on a fairly frequent basis (mean $6.81 \pm 2.52$ of 10 ), although many of the adolescents $(n=16)$ reported difficulties completing the yoga on a daily basis due to other commitments (eg, school work, chores). Several of the adolescents $(n=7)$ reported that it was difficult for them to practice the yoga when they were not feeling well. "When I was in pain the program was harder to do, but nothing would have made the actual program easier."

Regardless, the adolescents indicated that the yoga was generally quite helpful (mean $7.18 \pm 2.46$ of 10 ); they spontaneously reported that the yoga increased feelings of relaxation and calm $(n=12)$, decreased pain $(n=13)$, improved sleep $(n=3)$ and increased energy or concentration $(n=4)$. In addition, the adolescents reported that the yoga was very enjoyable (mean $8.24 \pm 2.07$ of 10 ) and easy to do (mean $9.16 \pm 1.32$ of 10$)$. All but one of the adolescents $(n=24)$ reported that they planned to continue to use the yoga to manage their IBS in the future.
TABLE 3

Results of paired sample $t$ tests comparing pre- and postintervention data after combining the two groups into one sample

\begin{tabular}{lccc}
\hline & $\begin{array}{c}\text { Preintervention } \\
\text { Mean } \pm \text { SD }\end{array}$ & $\begin{array}{c}\text { Postintervention } \\
\text { Mean } \pm \text { SD }\end{array}$ & $\begin{array}{c}\text { Paired samples } \\
\boldsymbol{t}(\mathbf{2 4})\end{array}$ \\
\hline Primary outcomes & & & \\
GI symptoms & $1.42 \pm 0.57$ & $0.93 \pm 0.66$ & $3.15, \mathrm{P}=0.004^{*}$ \\
Pain intensity & $5.73 \pm 2.32$ & $5.14 \pm 1.95$ & $1.34, \mathrm{P}=0.20$ \\
FDI & $28.89 \pm 13.29$ & $27.32 \pm 12.54$ & $0.86, \mathrm{P}=0.40$ \\
Secondary outcomes & & & \\
CDI & $3.72 \pm 3.83$ & $3.14 \pm 2.55$ & $1.25, \mathrm{P}=0.23$ \\
RCMAS & $12.60 \pm 6.03$ & $11.95 \pm 6.08$ & $1.28, \mathrm{P}=0.21$ \\
PCQ & & & \\
$\quad$ Emotion- & $1.46 \pm 0.85$ & $1.22 \pm 0.76$ & $2.82, \mathrm{P}=0.10^{*}$ \\
$\quad$ focused & & & \\
$\quad$ avoidance & & & \\
Distraction & $1.94 \pm 0.86$ & $1.97 \pm 0.94$ & $-0.35, \mathrm{P}=0.73$ \\
Approach & $1.87 \pm 0.67$ & $1.96 \pm 0.65$ & $-1.07, \mathrm{P}=0.29$ \\
\hline
\end{tabular}

*Significant at $P<0.10$. Note: The above data are based upon an $n=25$ with the exception of Children's Depression Inventory (CDI) and pain intensity which have $n=22$ due to missing values. FDI Functional Disability Inventory; GI Gastrointestinal; PCQ Pain Coping Questionnaire; RCMAS Revised Child Manifest Anxiety Scale

\section{DISCUSSION}

Following the recent interest in mind-body approaches for assisting patients with IBS (10), the present paper reports the results of a preliminary randomized study of yoga as an intervention for adolescents with IBS. Adolescents in the yoga group tended to report lower levels of functional disability, fewer emotion-focused avoidance pain coping strategies (ie, internalizing and externalizing), and less overall anxiety than adolescents in the control group. Additionally, after the control group received the yoga intervention and their pre- and postintervention data were merged with those of the yoga group, adolescents across both groups reported significantly lower levels of gastrointestinal symptoms and tended to report lower levels of emotion-focused coping. The results of these parallel sets of analyses, using both between-subject and withinsubject analytical approaches, provides converging evidence for the benefits of yoga among adolescents with IBS. These findings are consistent with those reported by Taneja et al (21) among adult patients with IBS and those reported by Raghavan et al (27) in a smaller sample of young adults, where positive effects of yoga were found on general well-being. Mind-body methods such as yoga, with its reliance on deep relaxed abdominal breathing and attention to comfort, may disrupt chronic patterns of functional disability, anxiety and maladaptive coping, which subsequently could reduce overall levels of gastrointestinal symptoms.

In addition to beneficial effects in various areas of functioning, as assessed using validated measures, the adolescents themselves reported the yoga intervention to be helpful, enjoyable and easy to do. "It gave me something new that I hadn't tried." "When I felt the pain coming on and did the yoga, the pain was less after the yoga." "I haven't missed nearly as much school. It makes me a lot happier too." "Though the pain is still there, you have done a lot to help me deal with it and control it, and I appreciate that a lot." The two most common areas in which the adolescents reported improvements 
included pain and feelings of relaxation or calm. Nearly all of the adolescents reported plans to continue using yoga as a strategy for managing their IBS. Despite this endorsement, a number of the adolescents reported barriers to completing the yoga practice on a daily basis, due to other commitments such as school work or chores, despite the relatively minimal time required (ie, approximately $10 \mathrm{~min}$ each day). Additional consideration will need to be given to how yoga interventions can be delivered in a way that is most feasible and enjoyable given adolescents' busy schedules. It is possible that more structure and peer interaction (eg, group classes) or individualized programs (which were not possible due to the video format of this intervention) may enhance adolescent motivation for completing daily yoga practice. A number of the participants stated that the program could have been more helpful for them if they had more yoga poses to choose from and if the video was longer. The video could be improved by providing an interactive digital video disc (DVD) where adolescents could select postures based on how they were feeling and where their pain (if any) was centralized.

The current study builds on this earlier work by using a randomized approach with a larger sample size and extends the recent findings among adult patients with IBS to a sample of adolescents. Although the relatively small sample size and corresponding low statistical power in the present study is a limitation, the positive effects reported in this paper are promising. The current study provides promising data regarding the potentially beneficial effects of yoga among adolescents with
IBS and highlights areas that should be assessed and issues that need to be considered in future research. For example, future randomized trials are needed with larger sample sizes to replicate and extend the results of the present study. It would also be important for future studies to extend the follow-up period beyond four weeks and explore alternate methods for delivering the yoga intervention. In the meanwhile, it appears that yoga is a mind-body approach found to be enjoyable by many adolescents with IBS; yoga shows promise as a valuable intervention for this population.

ACKNOWLEDGEMENTS: Thanks are extended to Dr Mark Kovacs and Ms Hardeep Dhaliwal for their assistance with participant recruitment, Marie Royer and Janice Clarfield for their assistance in development of the yoga video, Candice Johnson for assisting with the yoga instructional sessions, Dr Carl von Baeyer and Ms Kelly Hayton for their assistance with various aspects of this project, and Ms Sarah Peddle for her assistance with reanalysis of the data and editing of this manuscript. The authors are also grateful to the Division of Gastroenterology at the BC's Children's Hospital for their support and interest in this project. Dr Chambers is now in the Departments of Pediatrics and Psychology, Dalhousie University, Halifax, Nova Scotia where she holds a Canada Research Chair in Pain and Child Health. This research was supported by a private donation to Dr Kuttner and an establishment award from the British Columbia Research Institute for Children's and Women's Health to Dr Chambers. Dr Chambers was supported by career awards from the Canadian Institutes of Health Research and the Michael Smith Foundation for Health Research.

\section{REFERENCES}

1. Spollett GR. Irritable bowel syndrome: Diagnosis and treatment. Nurse Pract 1989;14:32-44.

2. Hyams JS, Burke G, Davis PM, Rzepski B, Andrulonis PA. Abdominal pain and irritable bowel syndrome in adolescents: A community-based study. J Pediatr 1996;129:220-6.

3. Goodman JE, McGrath PJ. The epidemiology of pain in children and adolescents: A review. Pain 1991;46:247-64.

4. Walker LS, Garber J, Greene JW. Psychosocial correlates of recurrent childhood pain: A comparison of pediatric patients with recurrent abdominal pain, organic illness, and psychiatric disorders. J Abnorm Psychol 1993;102:248-58.

5. Thompson WG, Longstreth GF, Drossman DA, Heaton KW, Irvine EJ, Muller-Lissner SA. Functional bowel disorders and functional abdominal pain. Gut 1999;45:1143-7.

6. Hyams JS, Hyman PE. Recurrent abdominal pain and the biopsychosocial model of medical practice. J Pediatr 1998;133:473-8.

7. Dickhaus B, Mayer EA, Firooz N, et al. Irritable bowel syndrome patients show enhanced modulation of visceral perception by auditory stress. Am J Gastroenterol 2003;98:135-43.

8. Mayer EA, Craske M, Naliboff BD. Depression, anxiety, and the gastrointestinal system. J Clin Psychiatry 2001;62:28-36.

9. Mayer, EA. Visceral and Nociceptive Sensory Information Processing in the Central Nervous System. Paper presented at the American and Canadian Pain Societies Joint Meeting, Vancouver, British Columbia, May 2004.

10. Mayer EA. Collaborative health for IBS. Clin Gastroenterol Hepatol 2003;1:423-4.

11. Saper RB, Eisenberg DM, Davis RB, Culpepper L, Phillips RS. Prevalence and patterns of adult yoga use in the United States: Results of a national survey. Altern Ther Health Med 2004:10:20-1.

12. Oken BS, Kishiyama MA, Zajdel D et al. Randomized controlled trail of yoga and exercise in multiple sclerosis. Neurology 2004;62:2058-64.

13. Collins C. Yoga: Intuition, preventive medicine, and treatment. J Obstet Gynecol Neonatal Nurs 1998;27:563-8.

14. Kaliappan L, Kaliappan KV. Efficacy of yoga therapy in the management of headaches. J Indian Psychol 1992;10:41-7.

15. Reilly R. Acute and prophylactic treatment of migraine. Nurs Times 1994;90:35-6.

16. Garfinkel MS, Singhal A, Katz WA, Allan DA, Reshetar R, Schumacher HR Jr. Yoga-based intervention for carpal tunnel syndrome: A randomized control trial. JAMA 1998;280:1601-3.

17. Garfinkel MS, Schumacher HR, Husain A, Levy M, Reshetar RA. Evaluation of a yoga based regimen for treatment of osteoarthritis of the hands. J Rheumatol 1994;21:2341-3.

18. Sathyaprabha TN, Murthy H, Murthy BT. Efficacy of naturopathy and yoga in bronchial asthma - a self controlled matched scientific study. Indian J Physiol Pharmacol 2001;45:80-6.

19. Murugesan R, Govindarajulu N, Bera TK. Effect of selected yogic practices on the management of hypertension. Indian J Physiol Pharmacol 2000;44: 207-10.

20. Williams KA, Petronis J, Smith D, et al. Effect of Iyengar yoga therapy for chronic low back pain. Pain 2005;115:107-17.

21. Taneja I, Deepak KK, Poojary G, Acharya IN, Pandey RM, Sharma MP. Yogic versus conventional treatment in diarrheapredominant irritable bowel syndrome: A randomized control study. Appl Psychophysiol Biofeedback 2004;29:19-33.

22. Savic K, Pfau D, Skoric S, Pfau J, Spasojevic N. The effect of Hatha yoga on poor posture in children and the psychophysiologic condition in adults. Med Pregl 1990;43:268-72.

23. Platania-Solazzo A, Field TM, Blank J, et al. Relaxation therapy reduces anxiety in child and adolescent pediatric patients. Acta Paedopsychiatrica 1992;55:115-20.

24. Harrison LJ, Manocha R, Rubia K. Sahaja yoga meditation as a family treatment programme for children with Attention DeficitHyperactivity Disorder. Clin Child Psychol Psychiatry 2004;9:479-97.

25. Telles S, Srinivas RB. Autonomic and respiratory measures in children with impaired vision following yoga and physical activity programs. Int J Rehabil Health 1998;4:117-22.

26. Jain SC, Rai L, Valecha A, Jha UK, Bhatnager SOD, Ram K. Effect of yoga training on exercise tolerance in adolescents with childhood asthma. J Asthma 1991;28:437-42.

27. Raghavan R, Nielson-Joseph A, Naliboff B, Zeltzer L. The effects of yoga in adolescents with irritable bowel syndrome: A pilot study. J Adolesc Health 2000;26:104. (Abst) 
28. Thompson WG, Dotevall G, Drossman DA, Heaton KW, Druis W. Irritable bowel syndrome: Guidelines for the diagnosis.

Gastroenterol Int 1989;2:92-5.

29. Boyce PM, Kolosky NA, Talley NJ. Irritable bowel syndrome according to varying diagnostic criteria: Are the new Rome II criteria unnecessarily restrictive for research and practice. Am J Gastroenterol 2000;95:3176-83.

30. Cohen J. Statistical Power Analysis for the Behavioural Sciences. 2nd edn. Hillsdale, NJ: Lawrence Erlbaum, 1988.

31. Blanchard EB, Scharff L. Psychosocial aspects of assessment and treatment of irritable bowel syndrome in adults and recurrent abdominal pain in children. J Consult Clin Psychol 2002;70;725-38.
32. Walker LS, Greene JW. The Functional Disability Inventory: Measuring a neglected dimension of child health status. J Pediatr Psychol 1991;16:39-58.

33. Reid GJ, Gilbert CA, McGrath PJ. The Pain Coping Questionnaire: Preliminary validation. Pain 1998;76:83-96.

34. Reynolds CR, Richmond BO. Revised Children's Manifest Anxiety Scale (RCMAS) manual. Los Angeles, CA: Western Psychological Services, 1985

35. Kovacs M. Children's Depression Inventory: Manual. New York: Multi-Health Systems, 1992.

36. Tabachnick BG, Fidell LS.Using Multivariate Statistics, 4th edn. Boston: Allyn and Bacon, 1996. 
Kuttner et al 


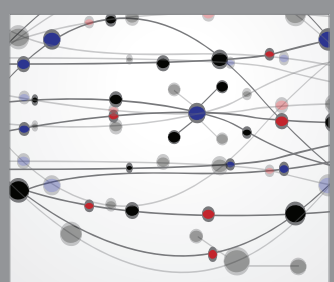

The Scientific World Journal
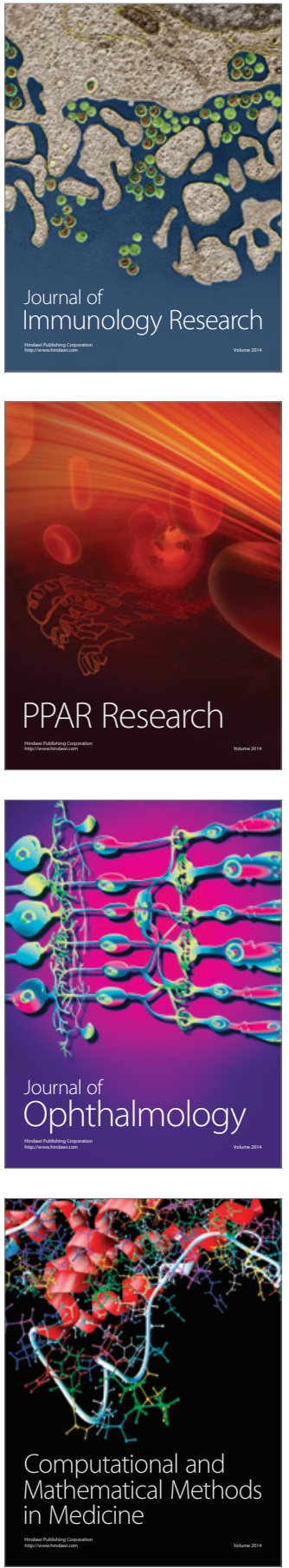

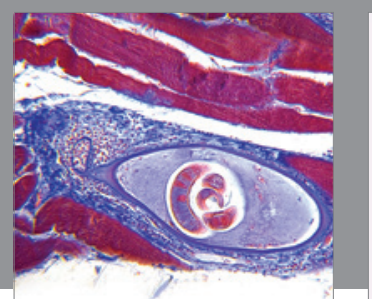

Gastroenterology Research and Practice

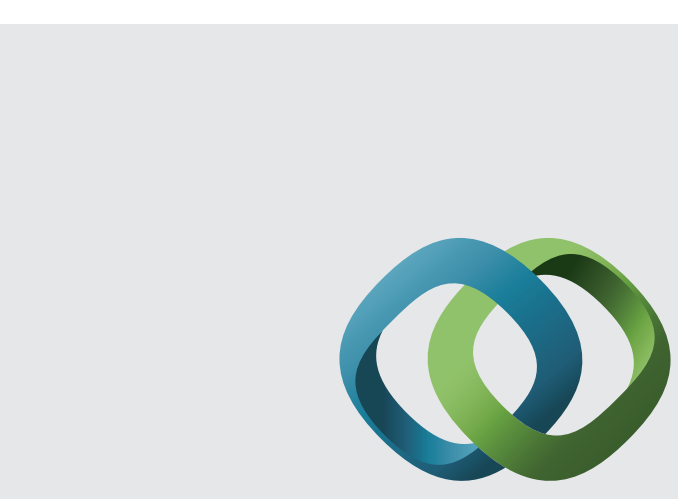

\section{Hindawi}

Submit your manuscripts at

http://www.hindawi.com
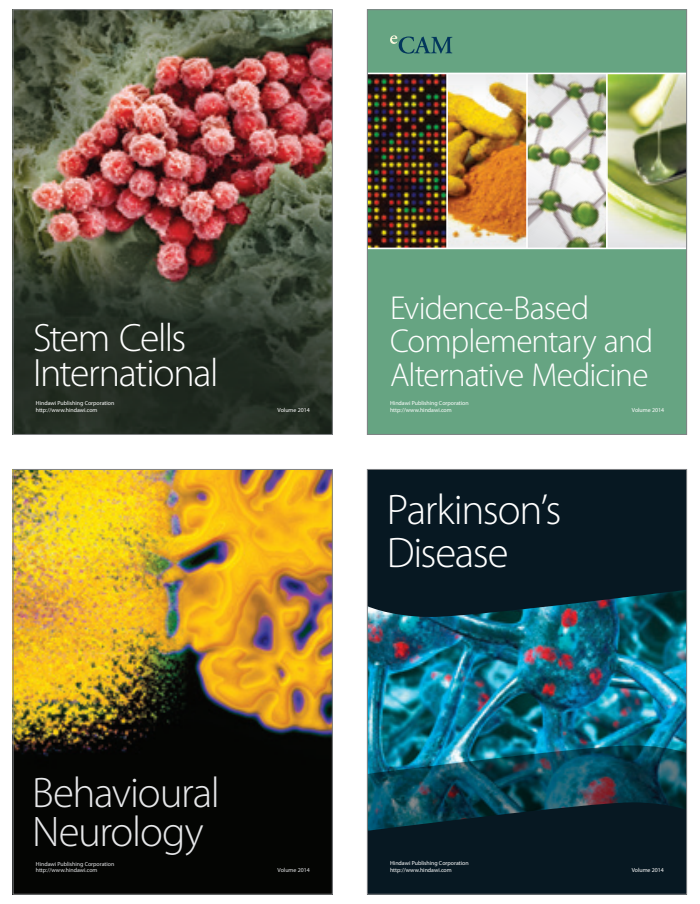
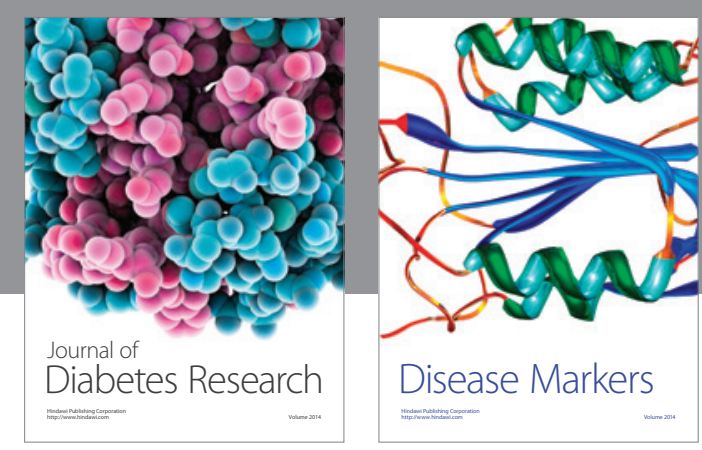

Disease Markers
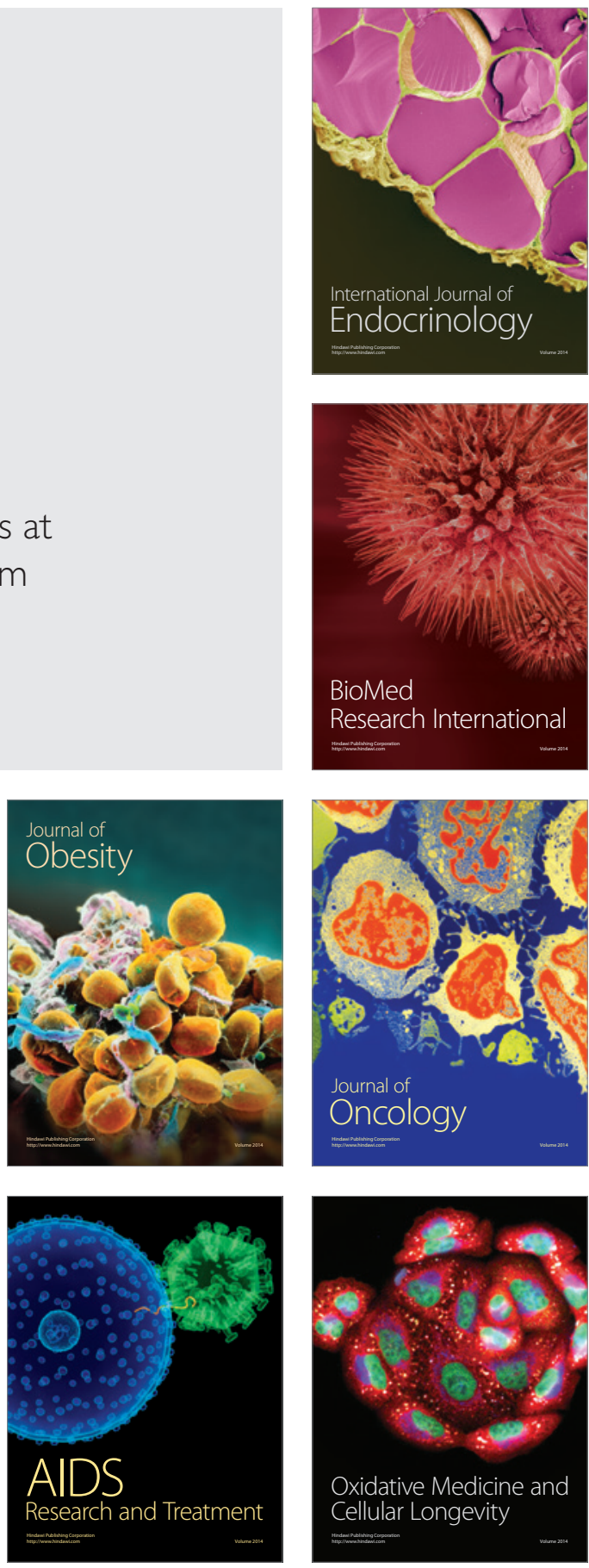